\title{
Applications of $\lambda$-Closed Sets in Intuitionistic Fuzzy Topological Space
}

\author{
P. Rajarajeswari \\ Assistant Professor, \\ Department of Mathematics \\ Chikkanna Government Arts college \\ Tirupur-641602
}

\author{
G. Bagyalakshmi \\ Assistant professor, \\ Department of Mathematics, \\ AJK College of Arts and science \\ Coimbatore -641105
}

\begin{abstract}
In this paper we study the relationship between $\lambda$-closed sets and some other intuitionisic fuzzy sets already exists. We also define intuitionistic fuzzy $\lambda$-irresolute map and study some of its properties.
\end{abstract}

\section{KEYWORDS}

Intuitionistic fuzzy topology, intuitionistic fuzzy $\lambda$-closed sets, intuitionistic fuzzy $\lambda$ - open sets, and intuitionistic fuzzy $\lambda$ irresolute maps.

\section{AMS SUBJECT CLASSIFICATION (2000) : 54A40, 03 F55}

\section{INTRODUCTION}

After the introduction of fuzzy sets by L.A Zadeh [17] in 1965 , there we have been a number of generalizations of this fundamental concept. The notion of intuitionistic fuzzy sets was introduced by Atanassov [1] in 1983. Using the notion of intuitionistic fuzzy sets, Coker [5] introduced the notion of intuitionistic fuzzy topology in 1997. This approach provides a wide field for investigation in the area of fuzzy topology and its application. The aim of this paper is to study the relations between intuitionistic fuzzy $\lambda$-closed sets and the other intuitionistic fuzzy sets already exists.Moreover we investigate intuitionistic fuzzy $\lambda$-irresolute map and study some of its properties

\section{PRELIMINARIES}

Definition 2.1: [1] Let $X$ be a nonempty set. An intuitionistic fuzzy set (IFS in short) $\mathrm{A}$ in $\mathrm{X}$ is an object having the form $\mathrm{A}$ $=\left\{<\mathrm{x}, \mu_{\mathrm{A}}(\mathrm{x}), v_{\mathrm{A}}(\mathrm{x})>: \mathrm{x} \in \mathrm{X}\right\}$, where the function $\mu_{\mathrm{A}}: \mathrm{X} \rightarrow$ $[0,1]$ and $v_{\mathrm{A}}: \mathrm{X} \rightarrow[0,1]$ denotes the degree of membership $\mu_{\mathrm{A}}(\mathrm{x})$ and the degree of non membership $\gamma_{\mathrm{A}}$ (x) of each element $\mathrm{x} \in \mathrm{X}$ to the set A respectively and $0 \leq \mu_{\mathrm{A}}(\mathrm{x})+v_{\mathrm{A}}(\mathrm{x})$ $\leq 1$ for each $\mathrm{x} \in \mathrm{X}$.

Definition 2.2 :[1]: Let A and B be intuitionistic fuzzy sets of the form

$\mathrm{A}=\left\{<\mathrm{x}, \mu_{\mathrm{A}}(\mathrm{x}), v_{\mathrm{A}}(\mathrm{x})>\mathrm{x} \in \mathrm{X}\right\}$, and form $\mathrm{B}=\left\{<\mathrm{x}, \mu_{\mathrm{B}}(\mathrm{x})\right.$, $\left.v_{\mathrm{B}}(\mathrm{x})>: \mathrm{x} \in \mathrm{X}\right\}$.Then

(a) $\mathrm{A} \subseteq \mathrm{B}$ if and only if $\mu_{\mathrm{A}}(\mathrm{x}) \leq \mu_{\mathrm{B}}(\mathrm{x})$ and $v_{\mathrm{A}}(\mathrm{x}) \geq v_{\mathrm{B}}(\mathrm{x})$ for all $\mathrm{x} \in \mathrm{X}$
(b) $\mathrm{A}=\mathrm{B}$ if and only if $\mathrm{A} \subseteq \mathrm{B}$ and $\mathrm{B} \subseteq \mathrm{A}$
(c) $\mathrm{A}^{\mathrm{c}}=\left\{\left\langle\mathrm{x}, v_{\mathrm{A}}(\mathrm{x}), \mu_{\mathrm{A}}(\mathrm{x})\right\rangle / \mathrm{x} \in \mathrm{X}\right\}$
(d) $\mathrm{A} \cap \mathrm{B}=\left\{\left\langle\mathrm{x}, \mu_{\mathrm{A}}(\mathrm{x}) \wedge \mu_{\mathrm{B}}(\mathrm{x}), v_{\mathrm{A}}(\mathrm{x}) \vee v_{\mathrm{B}}(\mathrm{x})\right\rangle / \mathrm{x} \in \mathrm{X}\right\}$

(e) $\mathrm{A} \cup \mathrm{B}=\left\{\left\langle\mathrm{x}, \mu_{\mathrm{A}}(\mathrm{x}) \vee \mu_{\mathrm{B}}(\mathrm{x}), v_{\mathrm{A}}(\mathrm{x}) \wedge v_{\mathrm{B}}(\mathrm{x})\right\rangle / \mathrm{x} \in \mathrm{X}\right\}$.

The intuitionistic fuzzy sets $0=\{\langle x, 0,1\rangle \mathrm{x} \in \mathrm{X}\}$ and $1=\{\langle x, 0,1\rangle \quad x \in X\}$ are respectively the empty set and whole set of $X$.

Definition 2.3 :[1]: Let $(\alpha, \beta) \in[0,1]$ with $\alpha+\beta \leq 1$, An intuitionistic fuzzy point (IFP), written as $\mathrm{p}_{(\alpha, \beta)}$ is defined to be IFS of $X$ given by

$$
\mathrm{p}_{(\alpha, \beta)}(\mathrm{x})= \begin{cases}(\alpha, \beta) & \text { if } \mathrm{x}=\mathrm{p} \\ (0,1) & \text { otherwise }\end{cases}
$$

Definition 2.4 : [5]: An intuitionistic fuzzy topology (IFT) on $\mathrm{X}$ is a family of IFSs which satisfying the following axioms.

(i)

$$
0, \quad 1 \in \tau
$$

$$
\mathrm{G}_{1} \cap \mathrm{G}_{2} \in \tau \text { for any } \mathrm{G}_{1}, G_{2} \in \tau
$$$$
\text { (iii) } \cup \mathrm{G}_{\mathrm{i}} \in \tau \text { for any family }\left\{\mathrm{G}_{\mathrm{i}} / \mathrm{i} \in \mathrm{I}\right\} \subseteq \tau
$$

In this case the pair $(X, \tau)$ is called an intuitionistic fuzzy topological space(IFTS) and each intuitionistic fuzzy set in $\tau$ is known as an intuitionistic fuzzy open set (IFOS for short )in X.

The complement A of an IFOS in an IFTS $(X, \tau)$ is called an intuitionistic fuzzy closed set (IFCS ) in $(\mathrm{X}, \tau)$.

Definition 2.5 : [5]: Let $(X, \tau)$ be an intuitionistic fuzzy topology and

$\mathrm{A}=\left\{<\mathrm{x}, \mu_{\mathrm{A}}(\mathrm{x}), v_{\mathrm{B}}(\mathrm{x})>: \mathrm{x} \in \mathrm{X}\right\}$, be an intuitionistic fuzzy set in $X$. Then the intuitionistic fuzzy interior and intuitionistic fuzzy closure are defined by

Int $(A)=\cup\{G / G$ is an intuitionistic fuzzy open set in $\mathrm{X}$ and $\mathrm{G} \subseteq \mathrm{A}\}$

$\mathrm{Cl}(\mathrm{A})=\cap\{\mathrm{K} / \mathrm{K}$ in an intuitionistic fuzzy closed set in $\mathrm{X}$ and $\mathrm{A} \subseteq \mathrm{K}$ \}

Remark 2.6 :[5]: For any intuitionistic fuzzy set A in (X, $\tau)$ , we have

(i) $\quad \mathrm{cl}\left(\mathrm{A}^{\mathrm{C}}\right)=[\operatorname{int}(\mathrm{A})]^{\mathrm{C}}$,

(ii) $\quad \operatorname{int}\left(\mathrm{A}^{\mathrm{C}}\right)=[\mathrm{cl}(\mathrm{A})]^{\mathrm{C}}$,

(iii) $\quad \mathrm{A}$ is an intuitionistic fuzzy closed set in $\mathrm{X} \Leftrightarrow \mathrm{Cl}$ $(\mathrm{A})=\mathrm{A}$ 
(iv)

$$
\begin{aligned}
& \text { A is an intuitionistic fuzzy open set in } \mathrm{X} \Leftrightarrow \text { int (A) } \\
& =\mathrm{A}
\end{aligned}
$$

Definition 2.7 :[6]: An intuitionistic fuzzy set $A=\left\{<x, \mu_{A}(x)\right.$, $\left.v_{\mathrm{B}}(\mathrm{x})>: \mathrm{x} \in \mathrm{X}\right\}$ in an intuitionistic fuzzy topology space $(\mathrm{X}, \tau)$ is said to be

(i) Intuitionistic fuzzy semi closed if int(cl (A) $\subseteq \mathrm{A}$.

(ii) Intuitionistic fuzzy pre closed if $\operatorname{cl}(\operatorname{int}(\mathrm{A})) \subseteq \mathrm{A}$.

Definition 2.8: An intuitionistic fuzzy set A of an intuitionistic fuzzy topological space $(X, \tau)$ called

(i)intuitionistic fuzzy generalized closed set [15] (intuitionistic fuzzy g - closed) if $\operatorname{cl}(\mathrm{A}) \subseteq \mathrm{U}$ whenever

$\mathrm{A} \subseteq \mathrm{U}$ and $\mathrm{U}$ is intuitionistic fuzzy semi open

(ii)intuitionistic fuzzy g - open set[14], if the complement of an intuitionistic fuzzy $\mathrm{g}-$ closed set is called intuitionistic fuzzy $\mathrm{g}$ - open set.

(iii)intuitionistic fuzzy semi open ( resp. intuitionistic fuzzy semi closed)[6] if there exists an intuitionistic fuzzy open (resp. intuitionistic fuzzy closed) such that $\mathrm{U} \subseteq \mathrm{A} \subseteq \mathrm{Cl}(\mathrm{U})$ ( resp. $\operatorname{int}(\mathrm{U}) \subseteq \mathrm{A} \subseteq \mathrm{U})$.

Remark 2.9 : [15]: Every intuitionistic fuzzy closed set (intuitionistic fuzzy open set) is intuitionistic fuzzy g- closed (intuitionistic fuzzy g- open) set) but the converse may not be true

Definition 2.10 An intuitionistic fuzzy set A of an intuitionistic fuzzy topological space $\left(\mathrm{X},{ }^{\tau}\right.$ ) is called

(i) an intuitionistic fuzzy w-closed [14] if $\operatorname{cl}(\mathrm{A}) \subseteq \mathrm{O}$ whenever $\mathrm{A} \subseteq \mathrm{O}$ and $\mathrm{O}$ is intuitionistic fuzzy semi open.

$$
\left(\mathrm{X},{ }^{\tau}\right)
$$

(ii) an intuitionistic fuzzy rw-closed set[16] if $\operatorname{cl}(\mathrm{A}) \subseteq \mathrm{O}$ whenever $\mathrm{A} \subseteq \mathrm{O}$ and $\mathrm{O}$ is intuitionistic fuzzy regular semi open. $(X, \tau)$

(iii) an intuitionistic fuzzy rg-closed $\operatorname{set}[16]$ if $\operatorname{cl}(\mathrm{A}) \subseteq \mathrm{O}$ whenever $\mathrm{A} \subseteq \mathrm{O}$ and $\mathrm{O}$ is intuitionistic fuzzy regular open. ( $\mathrm{X},{ }^{\tau}$ )

(iv) ) an intuitionistic fuzzy generalized $\alpha$-closed set [8] (IFG $\alpha \mathrm{CS}$ if $\alpha \mathrm{cl}(\mathrm{A}) \subseteq \mathrm{O}$ whenever $\mathrm{A} \subseteq \mathrm{O}$ and $\mathrm{O}$ is $\mathrm{IF} \alpha \mathrm{OS}$ in(

\section{$\mathrm{X},{ }^{\tau}$ )}

(iv) ) an intuitionistic fuzzy $\alpha$-generalized closed set [12] (IF $\alpha \mathrm{GCS}$ if $\alpha \mathrm{cl}(\mathrm{A}) \subseteq \mathrm{O}$ whenever $\mathrm{A} \subseteq \mathrm{O}$ and $\mathrm{O}$ is IFOS in ( $\mathrm{X}$,

$\tau$ )

Definition 2.11 :[12] An iuitionistic fuzzy set A of an intuitionistic fuzzy topological space $(X, \tau)$ called an

(i) intuitionistic fuzzy $\alpha$-open set ( IF $\alpha \mathrm{OS}$ in short ) if $\mathrm{A} \subseteq$ int (cl (int (A)))

(ii) ) intuitionistic fuzzy $\alpha$-closed set ( IF $\alpha \mathrm{CS}$ in short) if cl $(\operatorname{int}(\mathrm{cl}(\mathrm{A})) \subseteq \mathrm{A}$.

Definition 2.12 :[8] An iuitionistic fuzzy set A of an intuitionistic fuzzy topological space $(X, \tau)$ called intuitionistic fuzzy alpha generalised closed set ( IF $\alpha \mathrm{GCS}$ in short) if $\alpha \mathrm{cl}(\mathrm{A}) \subseteq \mathrm{U}$ and $\mathrm{U}$ is an IFOS in $(\mathrm{X}, \tau)$.

Definition 2.13 : [5] Let $\mathrm{X}$ and $\mathrm{Y}$ are nonempty sets and $\mathrm{f}$ : $\mathrm{X} \rightarrow \mathrm{Y}$ is a function.

(a) If $\mathrm{B}=\left\{<\mathrm{y}, \mu_{\mathrm{B}}(\mathrm{y}), v_{\mathrm{B}}(\mathrm{y})>: \mathrm{y} \in \mathrm{Y}\right\}$ is an

intuitionistic fuzzy set in $\mathrm{Y}$, then the pre image of $\mathrm{B}$

under $\mathrm{f}$ denoted by $\mathrm{f}^{-1}(\mathrm{~B})$, is defined by

$$
\mathrm{f}^{-1}(\mathrm{~B})=\left\{\left\langle\mathrm{x}, \mathrm{f}^{-1}\left(\mu_{\mathrm{B}}(\mathrm{x})\right), \mathrm{f}^{-1}\left(v_{\mathrm{B}}(\mathrm{x})\right)>: \mathrm{x} \in \mathrm{X}\right\}\right.
$$

(b) If $A=\left\{<\left\{x, \mu_{A}(x), v_{B}(x),\right)>/ x \in X\right\}$ is an intuitionistic fuzzy set in $X$, then the image of $A$ under $f$ denoted by $f(A)$ is the intuitionistic fuzzy set in $\mathrm{Y}$ defined by

$f(A)=\left\{\left\langle y, f\left(\mu_{A}(y)\right), f\left(v_{A}(y)\right)\right\rangle: y \in Y\right\}$ where $f\left(v_{A}\right)=1-$ $\mathrm{f}\left(1-\left(\mathrm{v}_{\mathrm{A}}\right)\right)$.

Definition 2.14: [10] An intuitionistic fuzzy set A of an intuitionistic topology space $(\mathrm{X}$,$) is called an$

(i) intuitionistic fuzzy $\lambda$-closed set (IF $\lambda$-CS) if A $\supseteq \operatorname{cl}(\mathrm{U})$ whenever $A \supseteq U$ and $U$ is intuitionistic fuzzy open set in $X$

(ii) intuitionistic fuzzy $\lambda$-open set (IF $\lambda$-OS) if the complement $A^{c}$ of an intuitionistic fuzzy $\lambda$-closed set

Definition $2.15:[13]$ Let $\mathrm{f}$ be a mapping from an IFTS (X, $\tau$ ) into an IFTS $(\mathrm{Y}, \sigma)$. Then $\mathrm{f}$ is said to be an

(i) intuitionistic fuzzy open mapping (IF open mapping) if $\mathrm{f}(\mathrm{A})$ is an IFOS in $\mathrm{Y}$ for every IFOS A in $\mathrm{X}$.

(ii) intuitionistic fuzzy closed mapping (IF closed mapping) if $\mathrm{f}(\mathrm{A})$ is an IFCS in Y for every IFCS A in X.

Definition 2.16 :[11] : A mapping $\mathrm{f}:(\mathrm{X}, \tau) \rightarrow(\mathrm{Y}, \sigma)$ is said to be intuitionistic fuzzy $\lambda$-continuous if the inverse image of every intuitionistic fuzzy closed set of $\mathrm{Y}$ is intuitionistic fuzzy $\lambda$-closed in $\mathrm{X}$

Definition $2.17:$ [11]: A topological space $(X, \tau)$ is called intuitionistic fuzzy $\lambda-\mathrm{T}_{1 / 2}$ space

( IF $\boldsymbol{\lambda}$-- $\mathrm{T}_{1 / 2}$ space in short) if every intuitionistic fuzzy $\lambda$ closed set is intuitionistic

fuzzy closed in $\mathrm{X}$.

\section{APPLICATIONS OF INTUITIONISTIC FUZZY $\lambda$-CLOSED SET.}

In this section we study the relations between Intuitionistic fuzzy $\lambda$-closed sets and some other Intuitionistic fuzzy sets already exists.

Definition3.1. Let A be an IFS in an IFTS $(X, \tau)$. Then the intuitionistic fuzzy $\boldsymbol{\lambda}$ - interior and intuitionistic fuzzy $\boldsymbol{\lambda}$ closure of A are defined as follows.

$\lambda$-int $(A)=U\{G \mid G$ is an IF $\lambda-O S$ in $X$ and $G \subseteq A\}$,

$\lambda$-cl(A) $=\cap\{\mathrm{K} \mid \mathrm{K}$ is an IF $\lambda-C S$ in $\mathrm{X}$ and $\mathrm{A} \subseteq \mathrm{K}\}$.

Theorem 3.2:Every IF preclosed set is IF $\lambda$-closed set .

Proof : Let A be a IF preclosed set. Let G is an IF open set such that $A \supseteq G$. Then $\operatorname{cl}(\operatorname{int}(A)) \supseteq \operatorname{cl}(\operatorname{int}(G)) \supseteq$ $\mathrm{cl}(\mathrm{G})$. Therefore $\mathrm{cl}(\operatorname{int}(\mathrm{A})) \supseteq \mathrm{cl}(\mathrm{G})$. Since A is IF preclosed set we have $\mathrm{A} \supseteq \operatorname{cl}(\operatorname{int}(\mathrm{A})) \supseteq \operatorname{cl}(\mathrm{G})$. Thus $\mathrm{A} \supseteq$ $\mathrm{cl}(\mathrm{G})$. Therefore $\mathrm{A}$ is IF $\lambda$-closed set. 
Remark 3.3 : The converse above theorem need not be true as seen from the following example.

Example3.4 : Let $X=\{a, b\}$ and $\tau=\{0,1, U\}$ be an intuitionistic fuzzy topology on X.where $U=\{\langle a, 0.5,0.5\rangle$, $<\mathrm{b}, 0.3,0.6>\}$. Then the intuitionistic fuzzy set

$\mathrm{A}=\{\langle\mathrm{a}, 0.5,0.5\rangle,\langle\mathrm{b}, 0.8,0.2\rangle\}$ is IF $\lambda$-closed set but not pre closed set.

Remark 3.5 : IF $\lambda$ - closed sets and IF w-closed sets are independent to each oter example

Example 3.6: Let $X=\{a, b\}$ and $\tau=\{0,1, U\}$ be an intuitionistic fuzzy topology on X.where $U=\{\langle\mathrm{a}, 0.5,0.5\rangle$, $\langle\mathrm{b}, 0.5,0.2\rangle\}$. Then the intuitionistic fuzzy set $\mathrm{A}=\{<\mathrm{a}, 0.5$, $0.5>,\langle\mathrm{b}, 0.5,0.4>\}$ is not intuitionistic fuzzy IF $\lambda$-closed set but not IF w-closed set

Example 3.7: Let $X=\{a, b\}$ and $\tau=\{0,1, U\}$ be an intuitionistic fuzzy topology on X.where $U=\{\langle a, 0.5,0.5\rangle$, $<\mathrm{b}, 0.4,0.6>\}$.Then the intuitionistic fuzzy set

$A=\{\langle a, 0.5,0.5\rangle,\langle b, 0.5,0.5\rangle\}$ is IF w-closed set not IF $\lambda$ closed set.

Remark 3.8 : IF $\lambda$ - closed sets and IF rw-closed sets are independent to each oter example
Example 3.9 Let $\mathrm{X}=\{\mathrm{a}, \mathrm{b}\}$ and $\tau=\{0,1, \mathrm{U}\}$ be an intuitionistic fuzzy topology on X.where $U=\{\langle a, 0.5,0.5\rangle$, $\langle\mathrm{b}, 0.5,0.2\rangle\}$. Then the intuitionistic fuzzy set $\mathrm{A}=\{\langle\mathrm{a}, 0.5$, $0.5\rangle,\langle\mathrm{b}, 0.5,0.4>\}$ is not intuitionistic fuzzy IF $\lambda$-closed set but not IF rw-closed set

Example 3.10 : Let $X=\{a, b\}$ and $\tau=\{0,1, U\}$ be an intuitionistic fuzzy topology on $X$.where $U=\{<a, 0.7,0.2\rangle$, $<\mathrm{b}, 0.6,0.3>\}$. Then the intuitionistic fuzzy set

$\mathrm{A}=\{\langle\mathrm{a}, 0.7,0.2\rangle,\langle\mathrm{b}, 0.6,0.3\rangle\}$ is IF rw-closed set but not IF $\lambda$-closed set.

Remark 3.11: IF $\lambda$-closed set and IF rg-closed set are independent to each oter example.

Example 3.12: Let $X=\{a, b\}$ and $\tau=\{0,1, U\}$ be an intuitionistic fuzzy topology on X.where $U=\{\langle a, 0.5,0.5\rangle$, $<\mathrm{b}, 0.5,0.2\rangle\}$. Then the intuitionistic fuzzy set $\mathrm{A}=\{<\mathrm{a}, 0.5$, $0.5>,\langle\mathrm{b}, 0.5,0.4>\}$ is not intuitionistic fuzzy IF $\lambda$-closed set but not IF rg-closed set

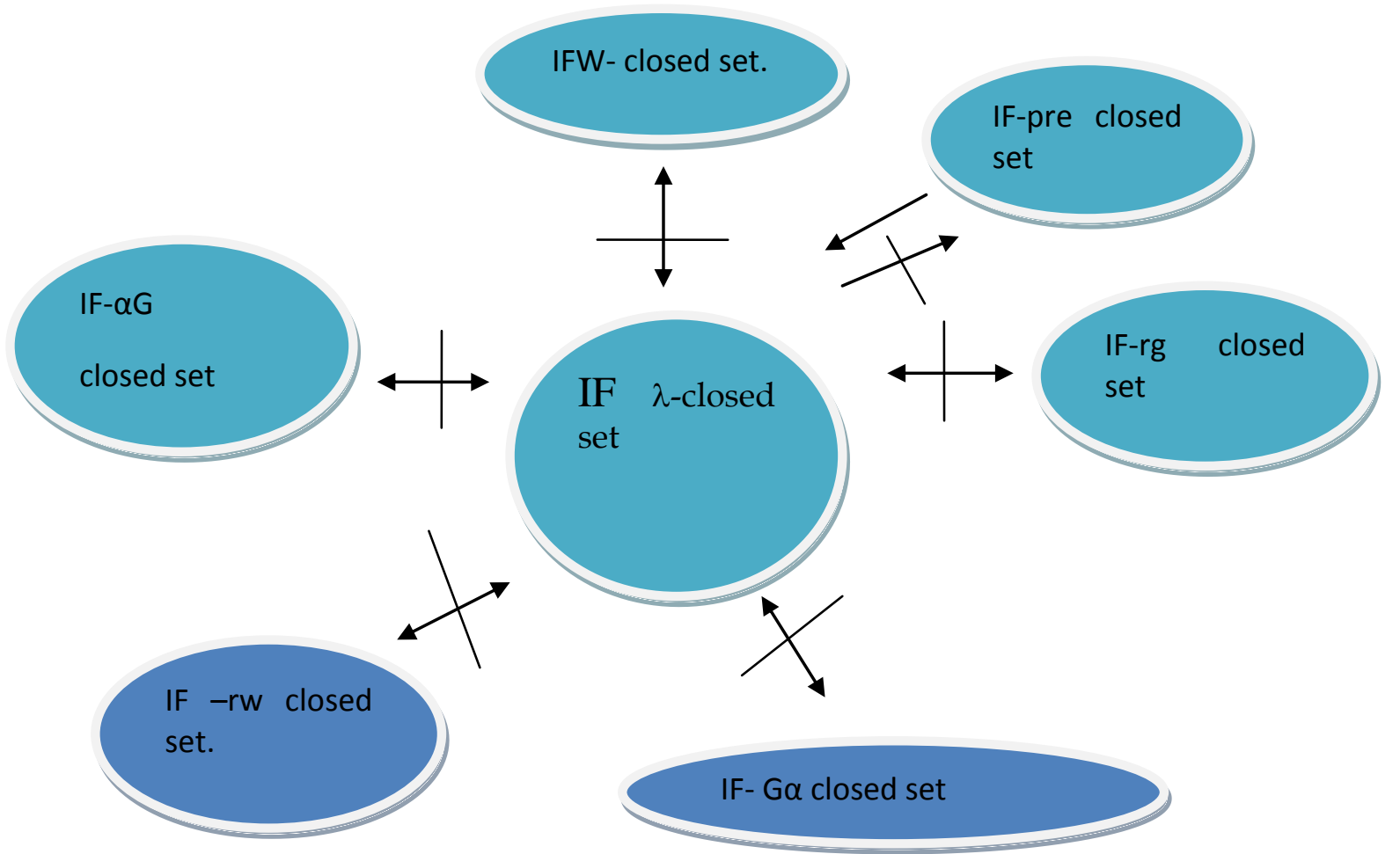


Example 3.13: Let $X=\{a, b, c, d\}$ and $\tau=\{\underset{\sim}{0,1, U, V, W}\}$ be an intuitionistic fuzzy topology on X.where $U=\{<a$, $0.7,0.2\rangle,\langle\mathrm{b}, 0.6,0.3\rangle,\langle\mathrm{c}, 0,1\rangle,\langle\mathrm{d}, 0,1\rangle\}$

$\mathrm{V}=\{\langle\mathrm{a}, 0.9,0.1\rangle,\langle\mathrm{b}, 0.8,0.1\rangle,\langle\mathrm{c}, 0,1\rangle,\langle\mathrm{d}, 0,1\rangle\}$,

$\mathrm{W}=\{\langle\mathrm{a}, 0.7,0.2\rangle,\langle\mathrm{b}, 0.6,0.3\rangle,\langle\mathrm{c}, 0,1\rangle,\langle\mathrm{d}, 0,1\rangle\}$

Then the intuitionistic fuzzy set $A=\{\langle a, 0,1\rangle,\langle b, 0,1\rangle,\langle c$, $0.7,0.2>,\langle d, 0,1>\}$ is IF rg-closed set but not IF $\lambda$-closed set

Remark3.14: $\mathrm{G} \alpha$ closed sets and IF closed sets are independent to each other for example

Example 3.15: Let $\mathrm{X}=\{\mathrm{a}, \mathrm{b}\}$ and $\tau=\{0,1, \mathrm{U}\}$ be an intuitionistic fuzzy topology on X.where $U=\{<a$, $0.2,0.8>,\langle\mathrm{b}, 0.3,0.7>\}$. Then the intuitionistic fuzzy set $\mathrm{A}=\{$ $\langle\mathrm{a}, 0.6,0.4>,\langle\mathrm{b}, 0.7,0.3>\}$ is IF Gaclosed set but not IF $\lambda$ closed set.

Example 3.16: Let $X=\{a, b\}$ and let and $\tau=\{0,1, \mathrm{U}\}$ be an intuitionistic fuzzy topology on $\quad X$.where $U=\{<a$, $0.8,0.2>,\langle\mathrm{b}, 0.8,0.1>\}$. Then the intuitionistic fuzzy set. $A=\{\langle a, 0.9,0.1\rangle,\langle b, 0.7,0.3\rangle\}$ is IF $\lambda$-closed set but is not IF Gaclosed set .

Remark :3.17 $\alpha \mathrm{G}$ closed sets and IF closed sets are independent to each other for example

Example 3.18: Let $\mathrm{X}=\{\mathrm{a}, \mathrm{b}\}$ and $\tau=\{0,1, \mathrm{U}\}$ be an intuitionistic fuzzy topology on $\quad X$.where $U=\{<a, 0.2,0.6$ $>,\langle\mathrm{b}, 0.2,0.7>\}$. Then the intuitionistic fuzzy set $\mathrm{A}=\{<$ $\mathrm{a}, 0.4,0.6>,<\mathrm{b}, 0.2,0.7>\}$ is IF $\alpha \mathrm{G}$ closed set but not IF $\lambda$ closed set.

Example 3.19: Let $X=\{a, b\}$ and $\tau=\{0,1, U$ \}be an intuitionistic fuzzy topology on $\quad X$.where $U=\{<a, 0.2,0.4$ $>,\langle\mathrm{b}, 0.3,0.5>\}$.Then the intuitionistic fuzzy set

$\mathrm{A}=\{\langle\mathrm{a}, 0.5,0.1\rangle,\langle\mathrm{b}, 0.6,0\rangle\}$ is IF $\lambda$-closed set but not IF $\alpha G$-closed set.

Remark 3.20 : From above examples and remarks we get following diagram of implications.

In this diagram $\mathrm{A} \longrightarrow \mathrm{B}$ means that $\mathrm{A}$ implies $\mathrm{B}$

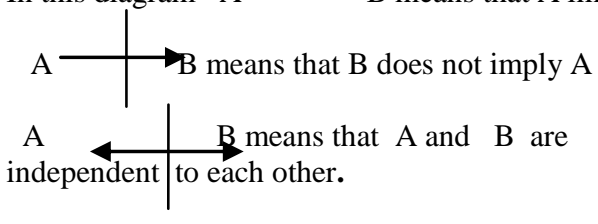

\section{4. $\lambda$ - irresolute mappings in intuitionistic fuzzy topological} spaces.

In this section we introduce intuitionistic fuzzy $\lambda$ - irresolute mapping and study some of its properties.

Definition 4.1: A mapping f: $\left(\mathrm{X},{ }^{\tau}\right) \rightarrow(\mathrm{Y}, \sigma)$ is called intuitionistic fuzzy $\lambda$-irresolute (IF- $\lambda$ - irresolute) if

$\mathrm{f}^{-1}(\mathrm{~V})$ is IF $\lambda$ - closed set is in $\left(\mathrm{X},{ }^{\tau}\right)$ for every IF $\lambda$ closed set $\mathrm{V}$ of $(\mathrm{Y}, \sigma)$

Theorem 4.2: If a mapping $\mathrm{f}:\left(\mathrm{X},{ }^{\tau}\right) \rightarrow(\mathrm{Y}, \sigma)$ is called IF $\lambda$ - irresolute mapping then it is IF $\lambda$-continuous mapping but not conversely.
Proof : Let V be any closed set in Y. since every closed set is IF $\lambda$ - closed set, $V$ is IF $\lambda$ - closed set in Y. By assumption $\mathrm{f}$

${ }^{1}(\mathrm{~V})$ is IF $\lambda$-closed set in $\mathrm{X}$. Thus $\mathrm{f}$ is IF $\lambda$-continuous.

The converse of the above theroem need not be true as seen in the following example:

Example 4.3: Let $X=Y=\{a, b\}$, and intuitionistic fuzzy sets $\mathrm{U}$ and $\mathrm{V}$ are defined as follows.

$\mathrm{U}=\{\langle\mathrm{a}, 0.5,0.5\rangle,\langle\mathrm{b}, 0.2,0.7\rangle\}$,

$\mathrm{V}=\{\langle\mathrm{a}, 0.5,0.5\rangle,\langle\mathrm{b}, 0.6,0.4\rangle\}$ be the intuitionistic fuzzy sets respectively and Let $\tau=\{\underset{\sim}{0}, \underset{\sim}{1}, \mathrm{U}\}$ and $\sigma=\{\underset{\sim}{0} \underset{\sim}{1}, \mathrm{~V}\}$ be intuitionistic fuzzy topologies on $\mathrm{X}$ and $\mathrm{Y}$ respectively. And let $\mathrm{f}:\left(\mathrm{X},{ }^{\tau}\right) \rightarrow(\mathrm{Y}, \sigma)$ be the identity mapping. Clearly $\mathrm{f}$ is IF $\lambda$ - continuous mapping. $\mathrm{f}^{-1}(\{<\mathrm{a}, 0.5,0.5\rangle,\langle\mathrm{b}, 0.4,0.6\rangle\}$ $=\{\langle a, 0.5,0.5\rangle,\langle b, 0.4,0.6\rangle\}$ in not IF $\lambda$-closed set in $\mathrm{X}$.Therefore $\mathrm{f}$ is not IF $\lambda$ - irresolute mapping.

Theorem $4 . .4$ : Let $\mathrm{X}, \mathrm{Y}$, and $\mathrm{Z}$ be any topological space. For any IF $\lambda$-irresolute map $\mathrm{f}:\left(\mathrm{X},{ }^{\tau}\right) \rightarrow(\mathrm{Y}, \sigma)$ and $\mathrm{IF} \lambda$ continuous map $\mathrm{g}:(\mathrm{Y}, \sigma) \rightarrow(\mathrm{Z}, \mathrm{v})$. The composition

$\mathrm{g}_{\mathrm{o}} \mathrm{f}:\left(\mathrm{X},{ }^{\tau}\right) \rightarrow(\mathrm{Z}, \mathrm{v})$ is IF $\lambda$-continuous.

Proof : Let $\mathrm{V}$ be any closed set in $\mathrm{Z}$. since $\mathrm{g}$ is IF $\lambda$ continuous map, $\mathrm{g}^{-1}(\mathrm{~V})$ is IF $\lambda$-closed in Y. Since IF $\lambda$-f is irresolute map $\mathrm{f}^{-1}\left(\mathrm{~g}^{-1}(\mathrm{~V})\right)$ is IF $\lambda$-closed in X.But

$\mathrm{f}^{-1}\left(\mathrm{~g}^{-1}(\mathrm{~V})\right)=(\mathrm{g} \circ \mathrm{f})^{-1}(\mathrm{~V})$ which is $\lambda$-closed in X.Thus $\mathrm{g} \circ \mathrm{f}$ is IF $\lambda$-continuous map.

Theorem 4.5 :If $\mathrm{f}:\left(\mathrm{X},{ }^{\tau}\right) \rightarrow(\mathrm{Y}, \sigma)$ is IF open mapping and IF continuous then $\mathrm{f}$ is IF $\lambda$ - irresolute map.

Proof : Let A be a $\lambda$-closed set in Y. Let $f^{-1}(A) \supseteq O$ where $\mathrm{O}$ is open in $\mathrm{X}$. since $\mathrm{f}$ is IF open,

$\mathrm{f}(\mathrm{O})$ is open in $Y$. Thus we have $A \supseteq f(O)$. This implies $A \supseteq$ $\mathrm{Cl}(\mathrm{f}(\mathrm{O}))$. But $\mathrm{cl}(\mathrm{f}(\mathrm{O}) \supseteq \mathrm{f}(\mathrm{cl}(\mathrm{O})$ because $\mathrm{f}$ is $\mathrm{IF}$ continuous.Therefore $A \supseteq f(\operatorname{cl}(\mathrm{O}))$. Hence $\mathrm{f}^{-1}(\mathrm{~A})$ is IF $\lambda$ closed set in X. Therefore f IF $\lambda$ - is irresolute.

Theorem:4. 6 :If $\mathrm{X}, \mathrm{Y}$ and $\mathrm{Z}$ are topological spaces.and $\mathrm{f}$ : ( $\left.\mathrm{X},{ }^{\tau}\right) \rightarrow(\mathrm{Y}, \sigma)$ and

$\mathrm{g}:(\mathrm{Y}, \sigma) \rightarrow(\mathrm{Z}, v)$ are IF $\lambda$-irresolute then composition $\mathrm{g} \circ \mathrm{f}$ $:\left(X,{ }^{\tau}\right) \rightarrow(Z, v)$ is IF $\lambda$-irresolute map.

Proof : Let V be a IF $\lambda$-closed set in $\mathrm{Z}$. Since $\mathrm{g}$ is IF $\lambda$ irresolute map, $\mathrm{g}^{-1}(\mathrm{~V})$ is IF $\lambda$-closed set in $(\mathrm{Y}, \sigma)$.Also we are given that $\mathrm{f}$ is IF $\lambda$-irresolute and therefore $\mathrm{f}^{-1} \mathrm{~g}^{-1}(\mathrm{~V})$ is

IF $\lambda$-closed set in $\left(X,{ }^{\tau}\right)$.But $f^{-1}\left(g^{-1}(V)\right)=(g \circ f)^{-1}(V)$. Hence $(g \circ f)$ is IF $\lambda$-irresolute map from $X$ to $Z$.

Theorem 4.7: Let $\mathrm{f}:(\mathrm{X}, \tau) \rightarrow(\mathrm{Y}, \sigma)$ be an IF $\lambda$ - irresolute, then $\mathrm{f}$ is an IF irresolute

mapping if $X$ is an IF $\lambda-T_{1 / 2}$ space.

Proof: Let A be an IFCS in Y. Then A is an IF $\lambda$-CS in Y. Therefore $\mathrm{f}^{-1}(\mathrm{~A})$ is an

IF $\lambda$-CS in $X$, by hypothesis. Since $X$ is an IF $\lambda$ - $T_{1 / 2}$ space, $\mathrm{f}^{-1}$ (A) is an IFCS in X. Hence. 
$\mathrm{f}$ is an IF irresolute mappings.

Theorem 4.8: Let $\mathrm{f}:(\mathrm{X}, \tau) \rightarrow(\mathrm{Y}, \sigma)$ be a mapping from an IFTS $\mathrm{X}$ into an IFTS Y.

Then the following conditions are equivalent if $\mathrm{X}$ and $\mathrm{Y}$ are IF $\lambda$ - $T_{1 / 2}$ spaces.

(i) $\mathrm{f}$ is an IF $\lambda$ - irresolute mapping

(ii) $\mathrm{f}^{-1}$ (B) is an IF $\lambda$-OS in $\mathrm{X}$ for each IF $\lambda$-OS in $\mathrm{Y}$

(iii) $\operatorname{cl}\left(\mathrm{f}^{-1}(\mathrm{~B})\right) \subseteq \mathrm{f}^{-1}(\mathrm{cl}(\mathrm{B}))$ for each IFS B of $\mathrm{Y}$.

Proof: (i) $\Longrightarrow$ (ii): It can be proved by using complement and definition 4.1.

(ii) $\Rightarrow$ (iii): Let $\mathrm{B}$ be any IFS in $\mathrm{Y}$ and $\mathrm{B} \subseteq \mathrm{cl}(\mathrm{B})$. Then $\mathrm{f}^{-1}$ (B) $\subseteq \mathrm{f}^{-1}(\mathrm{cl}(\mathrm{B}))$. Since $\mathrm{cl}(\mathrm{B})$

is an IFCS in $\mathrm{Y}, \mathrm{cl}(\mathrm{B})$ is an IF $\lambda$-CS in $\mathrm{Y}$. Therefore $\mathrm{f}^{-1}(\mathrm{cl}(\mathrm{B}))$ is an IF $\lambda$-CS in $\mathrm{X}$,

by hypothesis. Since $\mathrm{X}$ is IF $\lambda-\mathrm{T}_{1 / 2}$ space. $\mathrm{f}^{-1}(\mathrm{cl}(\mathrm{B}))$ is an IFCS in X. Hence

$\left.\operatorname{cl}\left(\mathrm{f}^{-1(}(\mathrm{B})\right) \subseteq \operatorname{cl~f}^{-1}(\operatorname{cl}(B))\right)=\mathrm{f}^{-1}\left(\operatorname{cl}(B)\right.$. That is $\left.\operatorname{cl~}^{-1}(B)\right) \subseteq$ $\mathrm{f}^{-1}(\mathrm{cl}(\mathrm{B}))$.

(iii) $\Rightarrow$ (i): Let B be an IF $\lambda$-CS in Y. Since Y is an IF $\lambda$ - $T_{1 / 2}$ space, $B$ is an IFCS in $Y$ and

$\operatorname{cl}(\mathrm{B})=\mathrm{B}$. Hence $\mathrm{f}^{-1} \quad(\mathrm{~B})=\mathrm{f}^{-1} \quad(\mathrm{cl}(\mathrm{B})) \subseteq \operatorname{cl}\left(\mathrm{f}^{-1} \quad(\mathrm{~B})\right)$. But clearly $\mathrm{f}^{-1}(\mathrm{~B}) \supseteq \operatorname{cl}\left(\mathrm{f}^{-1}\right.$ (B)).

Therefore $\operatorname{cl}\left(\mathrm{f}^{-1} \quad(\mathrm{~B})\right)=\mathrm{f}^{-1} \quad$ (B). This implies $\mathrm{f}^{-1}$ (B) is an IFCS and hence it is an IF $\lambda$-CSin $X$. Thus $f$ is an IF $\lambda$ irresolute mapping.

Theorem 4.9: Let $\mathrm{f}:(\mathrm{X}, \tau) \rightarrow(\mathrm{Y}, \sigma)$ be a an IF $\lambda$ - irresolute mapping from an IFTS X into an IFTS Y. Then $\mathrm{f}^{-1} \quad$ (B) $\subseteq \lambda$ $\operatorname{int}\left(\mathrm{f}^{-1}(\operatorname{cl}(\operatorname{int}(\operatorname{cl}(\mathrm{B}))))\right)$ for every IF $\lambda$-OS B in $\mathrm{Y}$, if $\mathrm{X}$ and $\mathrm{Y}$ are IF $\lambda$ - $T_{1 / 2}$ spaces.

Proof: Let B be an IF $\lambda$-OS in Y. Then by hypothesis $\mathrm{f}^{-1}$ (B) is an IF $\lambda$-OS in $X$. Since $X$ is an IF $\lambda-T_{1 / 2}$ space, $f^{-1}(B)$ is an IFOS in $\mathrm{X}$. Therefore $\lambda$ - $\operatorname{int}((\mathrm{B}))=(\mathrm{B})$. since $\mathrm{Y}$ is an IF $\lambda-\mathrm{T}_{1 / 2}$ space, $\mathrm{B}$ is an IF $\lambda$-OS in $\mathrm{Y}$ and $\mathrm{B} \subseteq \operatorname{cl}(\operatorname{int}(\operatorname{cl}(\mathrm{B})))$. Now $\mathrm{f}^{-1}$ $(\mathrm{B})=\lambda-\operatorname{int}\left(\mathrm{f}^{-1}(\mathrm{~B})\right)$ implies,

$\mathrm{f}^{-1}(\mathrm{~B}) \subseteq \lambda$-int $(\mathrm{f}(\operatorname{cl}(\operatorname{int}(\operatorname{cl}(\mathrm{B}))))$.

Theorem 4.10: If a mapping $\mathrm{f}: \mathrm{X} \rightarrow \mathrm{Y}$ is intuitionistic fuzzy $\lambda$--irresolute mapping, then

$\mathrm{f}(\lambda-\mathrm{cl}(\mathrm{B})) \subseteq \lambda-\operatorname{cl}(\mathrm{f}(\mathrm{B}))$ for every IFS B of X.

proof : Let B be an IFS of X. Since $\operatorname{cl}(\mathrm{f}(\mathrm{B}))$ is an IF $\lambda-\mathrm{CS}$ in $\mathrm{Y}$, by our assumption

$\mathrm{f}^{-1}(\mathrm{cl}(\mathrm{f}(\mathrm{B}))]$ is an IF $\lambda$-CS in $\mathrm{X}$. Furthermore $\mathrm{B} \subseteq \mathrm{f}^{-1}(\mathrm{f}(\mathrm{B}))$ $\subseteq \mathrm{f}^{-1}(\mathrm{cl}(\mathrm{f}(\mathrm{B})))$ and hence

$\lambda-\operatorname{cl}(\mathrm{B}) \subseteq \mathrm{f}^{-1}[\mathrm{cl}(\mathrm{f}(\mathrm{B}))]$ and consequently $\mathrm{f}[\lambda-\mathrm{cl}(\mathrm{B})] \subseteq \mathrm{f}\left[\mathrm{f}^{-}\right.$ $\left.{ }^{1}[\mathrm{cl}(\mathrm{f}(\mathrm{B}))]\right] \subseteq \mathrm{cl}(\mathrm{f}(\mathrm{B}))$.

Theorem4.11 : If any union of IF $\lambda$-CS is an IF $\lambda$-CS, then a mapping $\mathrm{f}: \mathrm{X} \rightarrow \mathrm{Y}$ from an IFTS

$\mathrm{X}$ into an IFTS $\mathrm{Y}$ is intuitionistic fuzzy $\lambda$ - -irresolute if and only if for each IFP $\mathrm{p}_{(\alpha, \beta)}$ in $\mathrm{X}$ and IF $\lambda$-CS B in Y such that $\mathrm{f}$ $\left(\mathrm{p}_{(\alpha, \beta)}\right) \in \mathrm{B}$, there exists an IF $\lambda$-CS A in X such that $\mathrm{p}_{(\alpha, \beta)} \in \mathrm{A}$ and

$\mathrm{f}(\mathrm{A}) \subseteq \mathrm{B}$.
Proof : Let $\mathrm{f}$ be any intuitionistic fuzzy-irresolute mapping, $\mathrm{p}_{(\alpha, \beta)}$ an IFP in $\mathrm{X}$ and $\mathrm{B}$ be any IF $\lambda$-CS in $\mathrm{Y}$, such that $\mathrm{f}$ $\left(\mathrm{p}_{(\alpha, \beta)}\right) \in \mathrm{B}$. Thenp $\mathrm{p}_{(\alpha, \beta)} \in \mathrm{f}^{-1}(\mathrm{~B})=\lambda$-cl[ $\left.\mathrm{f}^{-1}(\mathrm{~B})\right]$. We take

$A=\lambda$-cl $\left[\mathrm{f}^{-1}(\mathrm{~B})\right]$. Then $\mathrm{A}$ is an IF $\lambda$-CS in $\mathrm{X}$, containing IFP $\mathrm{p}_{(\alpha, \beta)}$ and

$\mathrm{f}(\mathrm{A})=\mathrm{f}\left[\lambda-\mathrm{cl}\left(\mathrm{f}^{-1}(\mathrm{~B})\right)\right] \subseteq \mathrm{f}\left[\mathrm{f}^{-1}(\mathrm{~B})\right] \subseteq \mathrm{B}$.

Conversely assume that $\mathrm{B}$ be any IF $\lambda$-CS in $\mathrm{Y}$ and IFP $\mathrm{p}_{(\alpha, \beta)}$ (x) in X, such that

$\mathrm{p}_{(\alpha, \beta)} \in \mathrm{f}^{-1}(\mathrm{~B})$. By assumption there exists IF $\lambda$-CS $A$ in $X$ such that $\mathrm{p}_{(\alpha, \beta)} \in \mathrm{A}$ and $\mathrm{f}(\mathrm{A}) \subseteq \mathrm{B}$. Therefore $\mathrm{p}_{(\alpha, \beta)}(\mathrm{x}) \in \mathrm{A} \subseteq$ $\mathrm{f}^{-1}(\mathrm{~B})$ and $\mathrm{p}_{(\alpha, \beta)} \in \mathrm{A}=\lambda-\operatorname{cl}(\mathrm{A}) \subseteq \lambda-\operatorname{cl}\left[\mathrm{f}^{-1}(\mathrm{~B})\right]$. Sincep $(\alpha, \beta)$ is an arbitrary IFP and $f^{-1}(B)$ is union of all IFP contained in $f^{-}$ ${ }^{1}(B), f^{-1}(B)$ is an IF $\lambda-C S$ in $X$, so $f$ is an intuitionistic fuzzy $\lambda$ irresolute mapping.

Corollary 4.12. A mapping $\mathrm{f}: \mathrm{X} \rightarrow \mathrm{Y}$ from an IFTS $\mathrm{X}$ into an IFTS Y is intuitionistic fuzzy

$\lambda$-irresolute if and only if for each IFP $p_{(\alpha, \beta)}$ in $\mathrm{X}$ and IF $\lambda$-CS $B$ in $Y$ such thatf $\left(\mathrm{p}_{(\alpha, \beta)}\right)$

$\epsilon B$, there exists an IF $\lambda$-CS $A$ in $X$ such that $p_{(\alpha, \beta)} \in A$ and $\mathrm{A} \subseteq \mathrm{f}^{-1}(\mathrm{~B})$.

Proof. Follows fromTheorem4.11

\section{CONCLUSION}

In this paper we have studied the relations between intuitionistic fuzzy $\lambda$-closed sets and the other intuitionistic fuzzy sets already exists.Also we studied the intuitionistic fuzzy $\lambda$-irresolute map and some of its properties.

\section{REFERENCES}

[1] Atanassov K. , Intuitionistic fuzzy sets in VII ITKR'S session (V. Sgurew, Ed) Sofita, Bulgaria (1983).

[2] Atanassov K. and S. Stoeva Intuitionistic fuzzy sets, In polish Symposium on interval and fuzzy Mathematics, Poznam (1983), 23 - 26.

[3] Atanassov K , Intuitionistic fuzzy sets, fuzzy setsandsystems 20 (1986), 87- 96.

[4] Chang C. L, Fuzzy topological spaces, J Mat. Anal. Appl. 24 (1968) $182-190$.

[5] Coker D. an introduction to Intuitionistic fuzzy topological space fuzzy sets and systems 88 (1997), $81-$ 99.

[6] Gurcay H., Coker D and ES., A Haydeer. "On fuzzy continuity in intuitionistic fuzzy sets topological spaces". The journal of fuzzy mathematical Vol. 5 No. 2, 365 781997).

[7] Joung Kon Jeon, Young Bae Jun, and Jin Han Park, Intuitionistic fuzzy alpha continuity and intuitionistic fuzzy pre continuity, international Journal of Mathematics and Mathematical sciences ,19 (2005),3091-3101

[8] Kalamani D.K ,sakthivel K and Gowri C.S , Generalized Alpha closed sets in Intuitionistic fuzzy Topological spaces. 
[9] Pushpalatha A. Ph.D thesis,"Studies on Generalizations of mappings in topological spaces" in Bharathiar University, Coimbatore.

[10] Rajarajeswari P. and Bagyalakshmi G. ' $\lambda$-closed sets in intuitionistic fuzzy topological space' International Journal of Computer Applications. (0975-34-No.1, November 2011

[11] Rajarajeswari P. and Bagyalakshmi G. ' $\lambda$-closed sets in intuitionistic fuzzy topological topological space' Foundation of Computer ScienceFCS, ewyork,Uo.1,November.2012.International Journal of Applied Information Systems (IJAIS)- ISSN : 22490868

[12] Sakthivel K.. Intuitionistic Fuzzy Alpha Generalized Continuous Mappings and Intuitionistic Alpha Generalised Irresolute Mappings. Applied Mathematical Sciences,Vol.4,2010, no.37,1831-1842.
[13] Santhi R and Jayanthi. R, Intuitionistic fuzzy generized semi- preclosed sets (accepted)

[14] Thakur S.S and Jyothi Pandey Bajpai, Intuitionistic fuzzy w- closed and Intuitionistic Fuzzy w-continuity, International Journal of contemporary Advanced Mathematics (IJCM), Volume (1): Issue (1).

[15] Thakur S.S and Rekha Chaturvedi, Regular generalized closed sets in intuitionistic fuzzy topological spaces,Universitatea Din Bacae .Studii Si cercetari Seria : Mathematica, 2006,257-272

[16] Thakur S.S and Jyothi Pandey Bajpai, Intuitionistic fuzzy rw closed and Intuitionistic Fuzzy rw-continuity, Fifteenth Int. Conf. on IFSs, Burgas, 11-12 May 2011NIFS 17 (2011), 2, 82-96

[17] Zadeh L.A, Fuzzy Sets information and Control , 18 ,338-353.(1965) 